\title{
DOMÍNIOS GEOMORFOLÓGICOS E MODIFICAÇÕES DO ESPAÇO AGRÍCOLA DE \\ BARREIRAS-BA:APLICAÇÕES DE GEOPROCESSAMENTO NO ESTUDO DOS CONDICIONANTES FÍSICOS DA EVOLUÇÃO DO USODO SOLO EM UM PÓLO SOJICULTOR
}

\author{
Brenner Maia-Rodrigues* \\ Miguel Fernandes Felippe \\ Alfredo Costa" \\ Aguirre Chaves" \\ Paulo Borges $\epsilon^{€}$
}

\section{Resumo}

O presente trabalho tem por objetivo verificar a distribuição espacial das atividades agrícolas nomunicípio de Barreiras a partir de imagens de satélites nos anos de 1979 e 2006. A disponibilidade hídrica e a presença de grandes áreas aplainadas foram alguns dos fatores que incentivaram o crescimento da área plantada na região das chapadas. Buscou-se verificar a expansão das atividades agrícolas nos diferentes domínios morfológicos identificados em Barreiras, que condicionam diretamente tais atividades. Faz-se necessário ressaltar também que o aumento expressivo da área plantada ocorrido nesse intervalo de tempo resultou numa grande pressão sobre os recursos naturais. Verificou-se remoção da vegetação natural em uma grande parcela do território estudado, além de diversos outros impactos verificados em campo.

Palavras-chave:Barreiras, Atividade agrícola, morfologia.

\begin{abstract}
The objective of this paper is to verify the spatial distribution of agricultural activities in the municipaldistrict of Barreiras/BA, according to sattelite images from the years 1979 and 2006. The hidricalavailability and the presence of extensive plain areas were some of the factors that incited the growthof the cultivated area in the chapada region. Due to these facts, the verification of the expansion ofagricultural activities in each of the distinct morphological domains that condition those activitiesdirectly and were identified in Barreiras/BA, was initiated. Thus, it becomes necessary to depict theexpressive growth in crop areas elapsed in the last 27 years, which resulted in increased pressureover the local natural resources. It was also verified the remotion of the endemic vegetal cover in agreat parcel of the studied territory, aside many other impacts verified on field.
\end{abstract}

Key words: Barreiras city, agricultural activity, morphology.

\footnotetext{
*Graduando de Geografia IGC/UFMG; bhmrodrigues@yahoo.com.br

- Mestrando em Geografia e Análise Ambiental IGC/UFMG; felippe@ufmg.br

`Graduando de Geografia IGC/UFMG; alfredo.ufmg@yahoo.com.br

• Graduando de Geografia IGC/UFMG; farsil.luhal@gmail.com

€ Graduando de Geografia IGC/UFMG; paulinho_borges@yahoo.com.br 


\section{1- INTRODUÇÃO}

O município de Barreiras ${ }^{1}$, no noroeste da Bahia, sofreu grandes transformaçõesem seu espaço nas últimas duas décadas, sobretudo pela expansão da sojicultura. Os indicadores econômicos colocam-no como um dos principais centros regionais da bacia doSão Francisco (Matos et al., 2007), refletindo os fluxos convergentes oriundos da ocupação da agroindústria em seu território, como demonstram vários trabalhos (Oliveira, 2007).

Todavia, interpretações superficiais não abarcam questões cruciais para acompreensão dos fenômenos geográficos. As diferenciações intra-municipais são, mormente, ignoradas e, com isso, os condicionantes físicos locais e regionais são ocultados. A compartimentação geomorfológica de Barreiras é uma característica essencial na espacialização do uso do solo, influenciando diretamente a aptidão agrícola das terras, principalmente em termos de facilidade de mecanização e disponibilidade hídrica.

Relações do meio físico com as atividades humanas são constantemente tachadas de “deterministas"; termo que carrega estigmas históricos desde Ratzel, no século XIX (Moreira, 1996). Não obstante, é inegável que há uma clara influência das características do sítio na distribuição espacial das atividades agrícolas no município de Barreiras. Dessa forma, o trabalho propõe-se a avaliar a evolução do uso do solo nos diferentes compartimentos geomorfológicos do município de Barrreiras, buscando compreender como a morfologia influenciou na transformação do espaço natural nas últimas décadas.

A primeira parte do trabalho apresenta uma compartimentação geomorfológica do município, que foi a base para o cruzamento das informações espaciais. Em um segundo momento, é realizada uma sucinta caracterização histórico-econômica da agricultura de Barreiras, embasada em dados do IBGE. Posteriormente, a evolução do uso do solo no município é mapeada a partir de imagens de satélite, possibilitando, finalmente, a comparação entre as unidades morfológicas quanto às modificações nelas ocorridas no uso do solo, objetivo primeiro do trabalho.

\section{2- PROCEDIMENTOS METODOLÓGICOS}

A compartimentação morfológica municipal foi realizada a partir do geoprocessamento de bases digitais de topografia, hidrografia, geologia, pedologia e imagens de satélite Landsat obtidas junto à CPRM (2004). O tratamento digital de imagens de satélite foi, também, o procedimento utilizado para

\footnotetext{
${ }^{1}$ Para fins de tratamento espacial das informações, o município de Barreiras neste trabalho inclui o atualmunicípio de Luís Eduardo Magalhães, emancipado daquele em 2002.
} 
a espacialização dos usos da terra. Nesse caso, foram escolhidas imagens Landsat (agosto de 1979) e Cbers(agosto de 2006). A vetorização das imagens foi assistida, minimizando possíveis erros da interpretação automática.

Para uma análise mais confiável, foram utilizados dados do IBGE ofertados pelo SIDRA ${ }^{2}$. Tais informações permitem a diferenciação de culturas agrícolas com maior precisão que a fornecida pelo sensoriamento remoto. Concomitantemente, foi realizada uma densa revisão bibliográfica sobre o tema. Adiciona-se que em janeiro de 2007 foi realizado umtrabalho de campo no município que contribuiu imensamente para a realização do trabalho.

\section{3- COMPARTIMENTAÇÃO MORFOLÓGICA DE BARREIRAS}

O município de Barreiras localiza-se no noroeste do estado da Bahia, na bacia do rio Grande, um dos principais afluentes da margem esquerda do rio São Francisco. Regionalmente, seu território é caracterizado por dois compartimentos do relevo: a leste, as terras de menor altimetria, se inserem nos Patamares do rio São Francisco; a oeste, a maior parte do município encontra-se nas Chapadas do rio São Francisco (IBGE, 2006).

Todavia, essa caracterização não é suficiente para avaliar as peculiaridades do relevo local, fazendo-se necessária uma nova compartimentação que abrevie as imprecisões ao ampliar a escala. Com base na interpretação do mapa topográfico (base digital da ANA) e imagens de satélite Landsat 5, associadas às informações geológicas (CPRM, 2004), pedológicas (IBGE, 2001) e trabalhos de campo, foi elaborado o mapa de unidades morfológicas de Barreiras (Figura 1).

Corroborando a compartimentação do IBGE (2006) a maior parte do município encontra-se nas Chapadas. Essa unidade é embasada por arenitos do Grupo Urucuia, da Província do São Francisco. A declividade é muito baixa, sendo considerável apenas nas áreas marginais aos canais de drenagem. Os vales são abertos e pouco encaixados promovendo, constantemente, grandes áreas alagadas e inúmeras veredas.

Entretanto, com o intuito de melhor caracterizar essa unidade em termos ambientais, foi evidenciada a região do Alto das Chapadas, delimitada pela altitude de 800 metros. Apesar de possuir características morfológicas muito similares à primeira, sua especificação busca evidenciar as pressões humanas sobre o ambiente, posto que a maior parte das nascentes e veredas da região se encontra nessa unidade, o que promove maior vulnerabilidade aos impactos ambientais, principalmente sobre os recursos hídricos. Além disso, predominam, nessas primeiras unidades morfológicas, solos do tipo Latossolo Amarelo, de baixa fertilidade, mas alta aptidão agrícola.

\footnotetext{
${ }^{2}$ Sistema IBGE de Recuperação de dados. Disponível em <www.sidra.ibge.gov.br> 


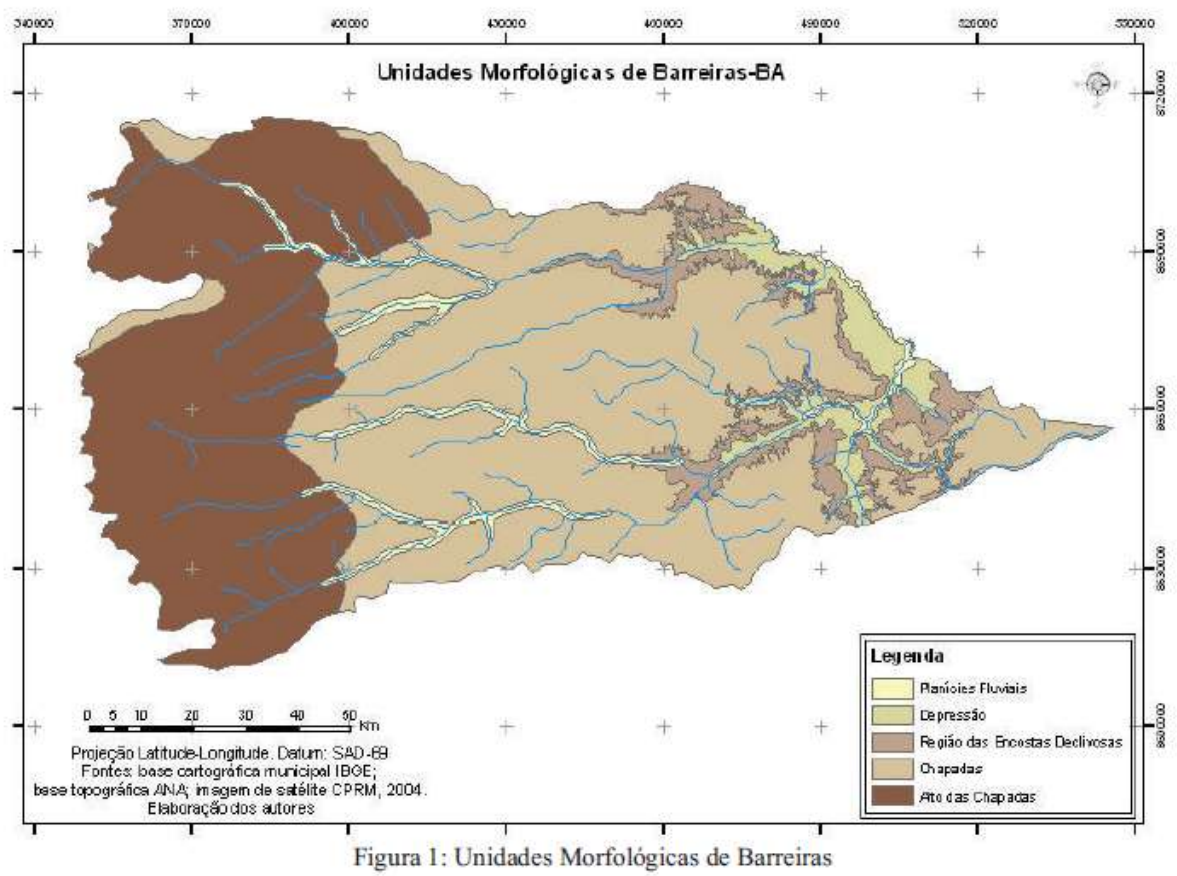

A unidade da Depressão foi assim determinada por apresentar-se em uma região deprimida, na porção nordeste do município. Corresponde ao que regionalmente foi considerado como Patamares (IBGE, 2006). A declividade é suave-ondulada, associada a rochas metamórficas do Grupo Bambuí, Formações Rianchão das Neves e Serra da Mamona - metarenitos e metarcóseos - e Coberturas Detrito-Lateríticascenozóicas (CPRM, 2004). Em termos pedológicos há uma grande variabilidade de solos, predominando LatossolosAmarelos, Neossolos - Quartzarênicos e Litólicos - e Cambissolos Háplicos (IBGE, 2001).

Uma unidade transicional - de grande importância em termos locais - entre a Chapada e a Depressão: a Região das Encostas Declivosas. Esse domínio caracteriza-se por uma elevada declividade, coincidindo, muitas vezes, com as escarpas das bordas das chapadas. Geologicamente é embasado, sobretudo, por metarenitos do Grupo Bambuí (CPRM, 2004). A alta declividade promove a predominância de Neossolos, sobretudo Litólicos (IBGE, 2001).

Por fim, a quinta unidade é composta pelas Planícies Fluviais. Com pequena abrangência espacial, esse domínio abarca parte significativa das margens do rio Grande e do rio de Janeiro e seus principais afluentes. Geologicamente são caracterizados por depósitos aluvionares recentes (CPRM, 2004). Nas áreas mal drenadas - encharcadas periodicamente - encontra-se Gleissolo Háplico (IBGE, 2001), como é o caso das veredas.

A Figura 2 ilustra essas unidades de relevo. A foto da esquerda mostra em primeiro plano a região das Encostas Declivosas e em segundo plano, as terras rebaixadas da Depressão. Ao fundo 
percebe-se o alinhamento de uma chapada extremamente plana. A segunda foto mostra os metarenitos que embasam o contato chapada/depressão.

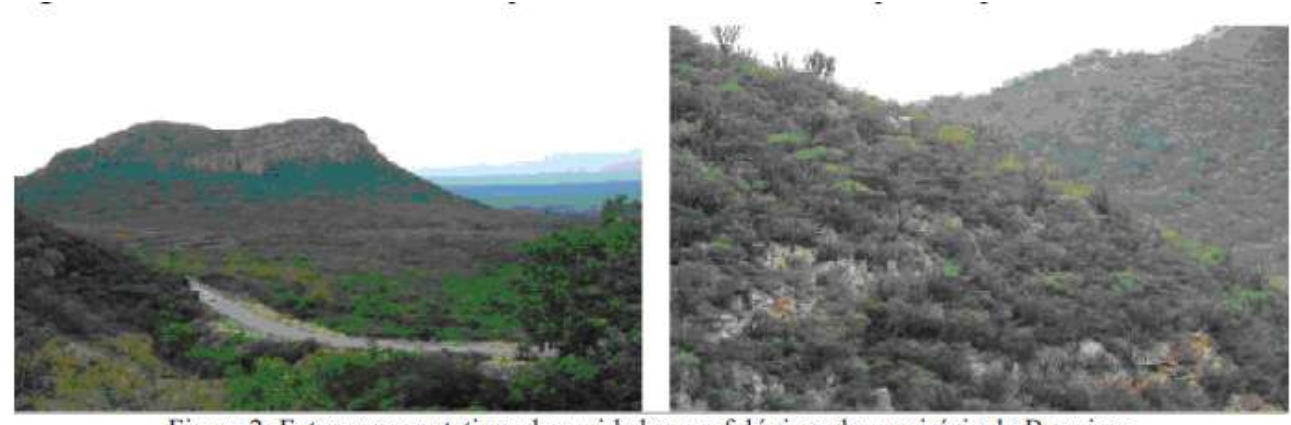

Figura 2: Fotos representativas das unidades morfológicas do município de Barreiras.

\section{4- A AGRICULTURA DE BARREIRAS: A SOJICULTURA COMO FOCO}

Barreiras localiza-se na região fito fisionômica das Savanas (Cerrado) (IBGE, 2004) predominando os estratos Arbóreo e Parque - cuja ocupação recente foi e é fomentada pela atividade agroexportadora em franco desenvolvimento, como supracitado. Fundado em 1891, o município só foi assistir a um crescimento econômico significativo a partir de meados da década de 1970, com a junção entre a BR 020 (que liga Barreiras a Brasília) e a BR 242 (que corta o estado baiano de leste a oeste). A posterior instalação do Centro de Pesquisa Agropecuária do Cerrado (CPAC/EMBRAPA) foi determinante para o desenvolvimento do setor agrário regional, já que em seu âmbito foram realizados, entre outros, estudos sobre a baixa fertilidade dos solos, visando melhor adequá-los ao plantio. Posteriormente, um novo tipo de soja foi testado na região, e seu sucesso viabilizou a expansão significativa de suas lavouras. (Oliveira, 2007)

Paralelamente, foi criada uma infraestrutura comercial e logística que incluiu a implantação de novas estradas (Matos \& Macedo, 2007). Deste modo, a expansão dos serviços atrelados à moderna agricultura foi centralizada em Barreiras. É nesta cidade que, atualmente, se encontram os fornecedores de máquinas e implementos agrícolas, bem como boa parte dos transportadores e compradores da produção. Neste contexto, destacam-se multinacionais do agronegócio, como a Bunge (Luís Eduardo Magalhães) e Cargill (Barreiras), que estão diretamente relacionadas à produção de soja. Entre $2000 \mathrm{e}$ 2005, aproximadamente 60\% dosrecursos do Fundo Constitucional de Financiamento do Nordeste (FNE) foi aplicado na Bahia, e o município de Barreiras se destacou por ter sido o sexto maior tomador de recursos dessa fonte, que em muito contribuiu para o avanço da agroindústria da região (Matos \&Macedo, 2007). 
A expansão da agricultura na região foi tão impressionante que, segundo dados da Produção Agrícola Municipal (PAM - IBGE), a área ocupada pela lavoura no município de Barreiras cresceu, entre 1990 e 2006, aproximadamente, dezessete vezes mais que a área ocupada pela lavoura no Brasil, e quase sete vezes mais que a do Estado da Bahia, demonstrando um grandioso interesse por parte de investidores no município (Tabela 1).

\begin{tabular}{l|l|l}
\hline \multicolumn{3}{c}{ Desenvolvimento da Área ocupada pela lavoura entre 1990 e 2006 } \\
\hline Localidade & Crescimento Médio (Ano) & Expansão da área em (\%) \\
\hline Brasil & 0,94 & 17,31 \\
Bahia & 2,11 & 42,53 \\
Barreiras - BA & 8,44 & 296,32 \\
\hline \multicolumn{3}{c}{ Tabela 1. Desenvolvimento da Area ocupada pela lavoura entre 1990 e 2006. } \\
\multicolumn{3}{r}{ Fonte: Produção Agrícola Municipal (PAM - IBGE) }
\end{tabular}

A soja teve um papel relevante nesse processo: em 1990, a área plantada pela sojarepresentava aproximadamente $77,8 \%$ da área total plantada, e mesmo depois do decréscimo da produção de soja na região em razão de alterações climáticas e a consequente diversificação da produção agrícola em 2002 (Cerqueira \& Rocha, 2002), a soja continuou tendo papel preponderante, representando aproximados 68,3\% da área total plantada no município. Ainda assim, mesmo com a expansão de outras culturas, principalmente a do milho, do algodão e do feijão, Barreiras possui parte considerável da área ocupada pela soja no Brasil (1,2\%). Além disso, a área de sojicultura em Barreiras cresceu praticamente duas vezes mais que em território nacional no período analisado (Tabela 2).

\begin{tabular}{l|l|l}
\hline \multicolumn{4}{c}{ Taxas de crescimento da área ocupada pela lavoura de Soja entre 1990 e 2006 } \\
\hline Localidade & Crescimento Médio (Ano) & Expansâo da área em (\%) \\
\hline Brasil & 3,87 & 90,62 \\
Bahia & 5,35 & 142,38 \\
Barreiras - BA & 7,61 & 248,05 \\
\hline Tabela 2. Taxas de crescimento da área ocupada pela lavoura de Soja entre 1990 e 2006.
\end{tabular}
Fonte: Produção Agricola Municipal (PAM - IBGE)

\section{5 - RESULTADOS: GEOMORFOLOGIA E ESPACIALIZAÇÃO DA EVOLUÇÃO DO USO DO SOLO EM BARREIRAS (1979-2006)}

Foi possível constatar que a área agrícola cresceu a uma taxa superior a da área urbana, e apesar da região do alto das chapadas ter apresentado a maior área ocupada pela agricultura, foi na área de planície que a agricultura cresceu com maior vigor (Tabela 3). A distribuição espacial desse crescimento pode ser verificada a partir da Figura 3 e Figura 4. A área urbana se faz mais presente nas chapadas, e 
apesar da cidade ter se deslocado de modo mais intenso para as encostas declivosas, essa mesma região foi a que mais preservou, proporcionalmente, as áreas de cerrados, matas e capoeiras, por ser desfavorável para a agricultura e exigir maiores investimentos.

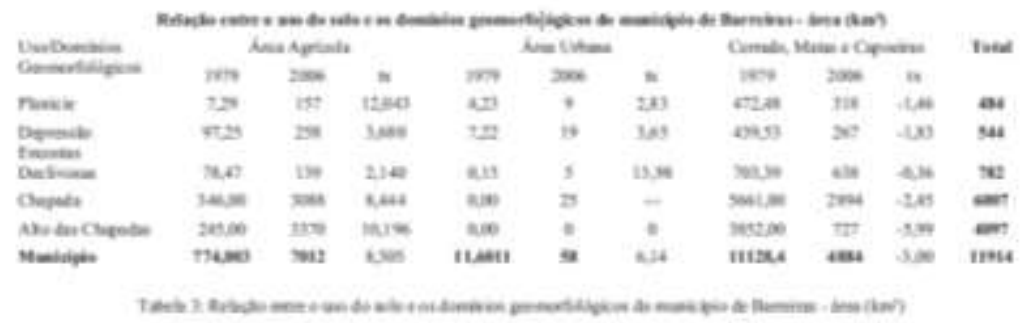

Em 1979 as áreas de chapada abrigavam 44,7\% da área agrícola no município, e essa proporção se manteve similar em 2006. Por outro lado, é interessante destacar que em 1979 o alto das chapadas abrigavam 31,65\% das áreas de agricultura do município, e em 2006 passou a ser responsável por praticamente metade dessa mesma área. A agroindústria teve papel fundamental nesse processo, pois a agricultura localizada nas depressões e encostas declivosas, próxima aos rios, representava 22,7\%, já que era realizada por pequenos produtores em minifúndios, e em 2006 passaram a representar apenas $5,66 \%$ da área ocupada pela agricultura no município.

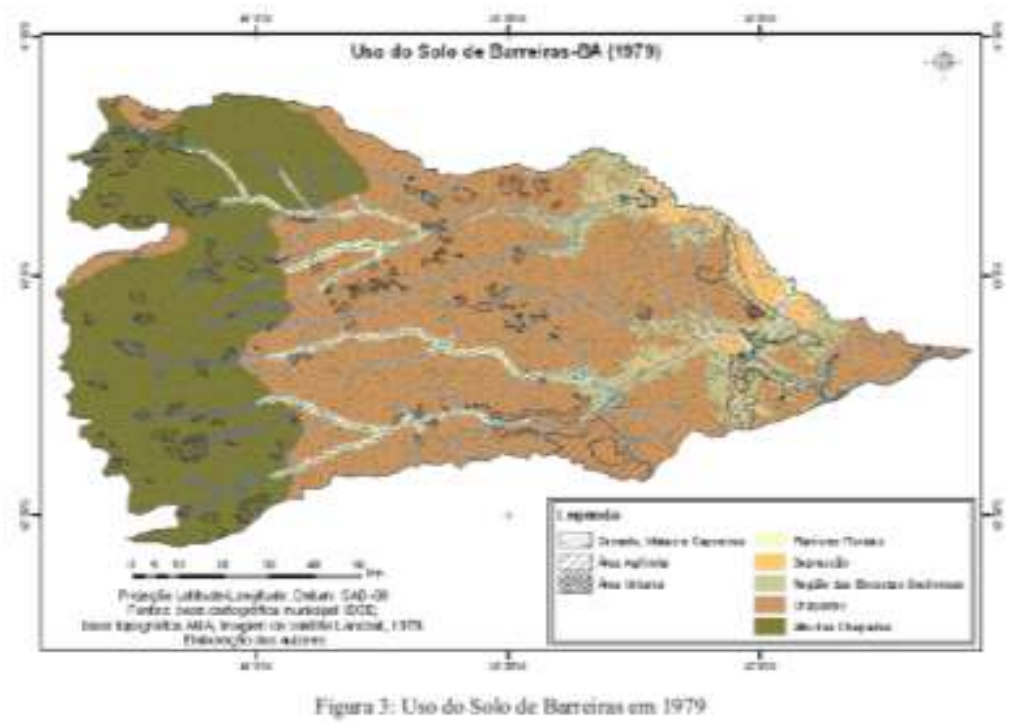




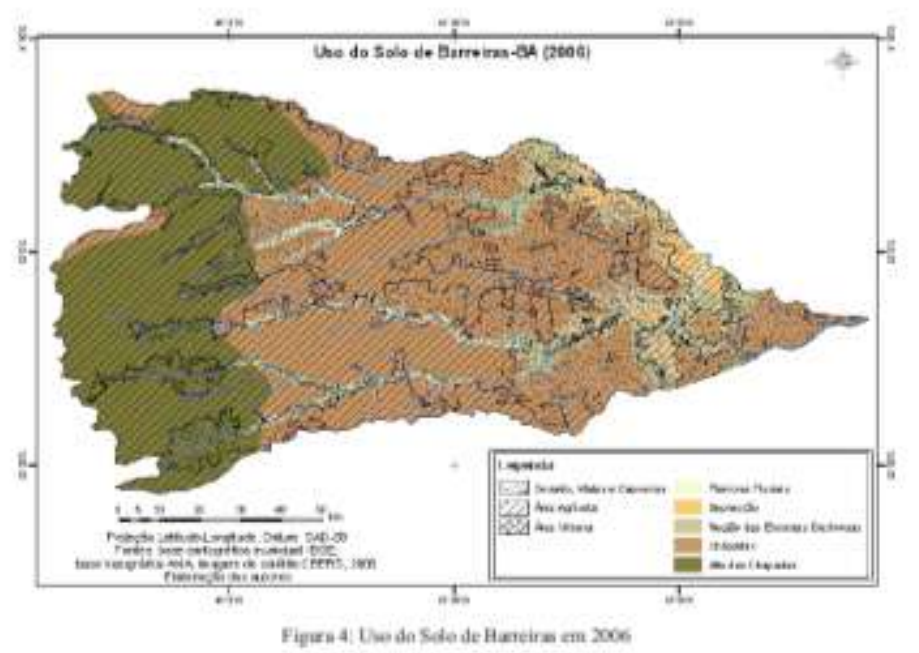

Neste mesmo sentido, foi possível observar que enquanto em 1979 a agricultura ocupava 5,98\% da área do alto das chapadas, em 2006 a agricultura passou a ocupar 82,26\% na mesma região. Nas planícies, as áreas proporcionalmente ocupadas pela agricultura aumentaram em mais de 21 vezes, e a área urbana se expandiu em todas as feições geomorfológicas, exceto no alto das chapadas. Ficou evidente que as áreas ocupadas pelocerrado, pelas matas e pelas capoeiras sofreram redução sensível, e em 2006 passaram a representar uma área equivalente a 43,9\% da área ocupada pelo cerrado, pelas matas e capoeiras em 1979, e que, como esperado, a grande responsável foi a agricultura industrial.

\section{6 - CONSIDERAÇÕES FINAIS}

A expansão da área agrícola no município de Barreiras apresentou um comportamento que possui estreita relação com as características morfológicas da região. Foi possível verificar, por exemplo, que o aumento da área agrícola foi maior nas planícies fluviais. Trata-se de uma constatação interessante, que pode estar associada as limitações das imagens utilizadas para representar o ano de 1979, visto que possuem uma resolução espacial bem inferior as imagens de 2006. Em 1979, pode-se verificar que as atividades agrícolas se concentravam nas planícies fluviais e nas suas proximidades, mas a pequena extensão de muitas das fazendas dificulta a identificação.

Já em 2006, a atividade agrícola desenvolvida no município já possuía um caráter voltado a exportação, ocupando grande parcela do território do município analisado. Os domínios identificados como Alto das Chapadas e como Chapadas, registraram uma diminuição significativa das áreas ocupadas por cerrados e outras formações vegetais. Nesses domínios, as características morfológicas favorecem a mecanização e a irrigação, atraindo grandes investidores e empresas multinacionais. 
Vale ressaltar, que em algumas áreas próximas aos cursos d'água, verificou-se um comportamento contrário, com a substituição de áreas agrícolas por formações vegetais associadas ao cerrado e as matas galerias. Tal comportamento pode indicar uma preocupaçãodos grandes produtores com a legislação ambiental e a implementação de novas tecnologias que facilitam a irrigação das culturas.

Por fim, vale salientar acerca da necessidade de que novos trabalhos sejam desenvolvidos nessa área, a fim de verificar como se deu o crescimento das atividades agrícolas no município e suas consequências nos mais diversos âmbitos. Deve-se buscardesde a identificação de impactos ambientais nos diferentes domínios morfológicos, até questões relacionadas a geopolítica local, que resultou na emancipação do município de LuisEduardo Magalhães, por exemplo. Trata-se de um contexto socioambiental extremamente complexo que merece ser melhor estudado e discutido.

\section{7 - REFERÊNCIAS}

Cerqueira, P. da S.; Rocha, A. G. (2002) O desempenho da agricultura no primeiro quadrimestre de 2002. Conjuntura \& Planejamento.

CPRM (2004). Carta geológica do Brasil ao milionésimo. CPRM, Rio de Janeiro.

IBGE (2001). Mapa de solos do Brasil. IBGE, Rio de Janeiro.

IBGE (2004). Mapa de vegetação do Brasil. IBGE, Rio de Janeiro.

IBGE (2006). Mapa de unidades de relevo do Brasil. IBGE, Rio de Janeiro. Oliveira, Pedro Valle de Carvalho e. A (2007) Rede de Localidades Centrais na Região do Médio Noroeste Baiano - Bacia do São Francisco. Monografia.

MATOS, Elmer N. ; Macedo, Fernando C. de . Avaliação do FNE no desenvolvimento regional Baiano no período pós-Real. Bahia Análise \& Dados, 2007.

MATOS, R; Lobo, C; Stefani, J; Braga, F; Oliveira, P. V.. (2007). Região, população e territorialidades chaves da rede de cidades da bacia do São Francisco. XII Encontro ANPUR. ANPUR, Belém.

MORAES, A. (1997) Geografia: pequena historia critica. 15ª ed. Hucitec, São Paulo. 